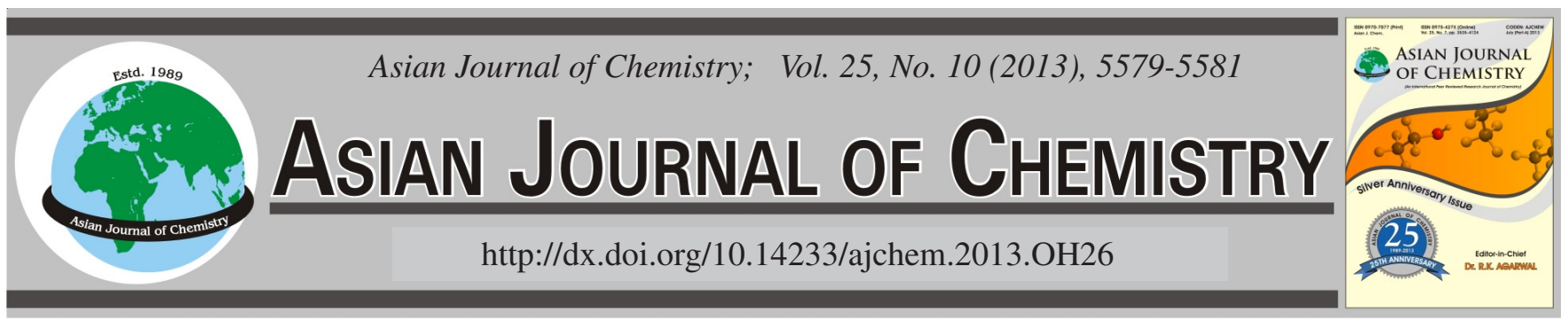

\title{
Preparation and Characterization of Porous Biphasic Calcium Phosphate for Biomedical Application $\dagger$
}

\author{
Yusong Pan ${ }^{*}$, Chuyang Xu and Huayuan Rong
}

Department of Material Science and Engineering, Anhui University of Science and Technology, Huainan 232001, P.R. China

*Corresponding author: E-mail: yusongpan@163.com

AJC-13269

\begin{abstract}
The porous biphasic calcium phosphate scaffolds was prepared by wet precipitation method combing with sintering technology. The microstructure and morphology were investigated by XRD, SEM and FTIR. The results revealed that the porous biphasic calcium phosphate scaffolds exhibit abundant porous structure and this special porous structure is beneficial to the growth of chondrocytes and effectively improves the interfacial bonding strength between implant material and natural tissue. The porosity of the scaffolds increased with the rise of stearic acid content. The investigation on the compressive mechanical properties revealed that the compressive strength of the porous biphasic calcium phosphate scaffolds decreased with the rise of stearic acid content and porosity.
\end{abstract}

Key Words: Porous biphasic calcium phosphate, Microstructure, Compressive strength.

\section{INTRODUCTION}

Due to their excellent biocompatibility and bioactivity, as well as similar inorganic constituents to the natural bone, hydroxyapatite, tri-calcium phosphate (TCP) and biphasic calcium phosphate consisting of hydroxyapatite and $\beta$-TCP have been widely used for filling bone defects ${ }^{1,2}$. Specifically for porous calcium phosphate bio-ceramics, they have been widely used in bone tissue engineering scaffolds due to their excellent bioactivity and 3-D interconnected pores which can stimulate the attachment, proliferation and differentiation of cells while implanted $^{3}$. A trend for scaffold materials is the development of compositionally and geometrically complex scaffolds to meet the strict property requirements. On the other hand, most in vitro studies have been recognized that biphasic calcium phosphate bio-ceramics containing hydroxyapatite and $\beta$-TCP phases have higher osteo-inductive potential than pure hydroxyapatite and tri-calcium phosphate ${ }^{4,5}$. However, these bio-ceramics often have relatively poor mechanical properties and easily fractured after implanting. This would limit their wider applications as bone substitutes and bone tissue engineering scaffolds.

In the present study, we attempted to prepare implantable biomaterials that are able to lead to bone formation and also can provide suitable mechanical properties. For this purpose, porous BCP ceramics were prepared with consisting of hydroxyapatite and $\beta$-TCP. The compressive strengths of the porous bio-ceramics were measured.

EXPERIMENTAL

BCP powder was prepared with $\mathrm{Ca}(\mathrm{OH})_{2}$ and $\mathrm{H}_{3} \mathrm{PO}_{4}$ as raw materials by direct precipitation method. The synthesis procedure involved the drop by drop introduction of the $\mathrm{H}_{3} \mathrm{PO}_{4}$ solution into an aqueous suspension of $\mathrm{Ca}(\mathrm{OH})_{2}$ while stirring vigorously for about $4 \mathrm{~h}$ at room temperature. The quantities of the reactants were selected to provide a $\mathrm{Ca} / \mathrm{P}$ molar ratio of 1.5. After reaction, the obtained white precipitate was left for $12 \mathrm{~h}$ and then decanted, rinsed with deionized water and filtrated. After filtration, the precipitate was dried in vacuum oven at $70^{\circ} \mathrm{C}$ for $12 \mathrm{~h}$. Finally, the dried precipitate was sintered in sintering furnace at $1100^{\circ} \mathrm{C}$ for $2 \mathrm{~h}$ and $\mathrm{BCP}$ powder was prepared after cooling to room temperature. Furthermore, in order to study the effects of calcining temperature on the synthesized powder, the dried precipitate was sintered at 300 , 600,900 and $1100{ }^{\circ} \mathrm{C}$ for $2 \mathrm{~h}$ in a conventional furnace under air atmosphere, respectively.

The stearic acid was selected as pore-forming agent and to construct the porous structure. Calcined BCP powder and stearic acid were prepared to fabricate the porous specimens. Considering different porosity, five different weight ratios of BCP powder and stearic acid (100:0, 85:15, 70:30, 55:45 and 40:60) were prepared and mixed by agitator milling for $1 \mathrm{~h}$. The mixture powders were uniaxially pressed in a die with cylinder type spaces of $13 \mathrm{~mm}$ diameter and $17 \mathrm{~mm}$ height under a pressure of $5 \mathrm{MPa}$ for $6 \mathrm{~min}$. Then, they were heated

$†$ Presented to the 6th China-Korea International Conference on Multi-functional Materials and Application, 22-24 November 2012, Daejeon, Korea 
at $200{ }^{\circ} \mathrm{C}$ for $2 \mathrm{~h}$ to eliminate moisture. The specimens were subsequently heated at $400{ }^{\circ} \mathrm{C}$ and $600{ }^{\circ} \mathrm{C}$ for $4 \mathrm{~h}$ and $3 \mathrm{~h}$ respectively to remove the stearic acid. After then, the specimens were sintered at $1000{ }^{\circ} \mathrm{C}$ for $4 \mathrm{~h}$ in the furnace. Finally, the specimens were cooled to room temperature in the furnace.

XRD experiments were performed on different calcining temperature of BCP powders with the diffractometer. Fourier transform infrared (FTIR) spectroscopy was used to identify the functional groups of BCP powders. Morphological characterization of the samples was observed by JSM-6700F scanning electron microscopy.

Each specimen was weighed and its actual size was measured by vemier calipers to determine its density and volume. The porosity $\mathrm{P}$ of the porous specimens was measured by Archimedes method.

The compressive strength measurements were performed on mechanical test equipment. The test strain rate of the sample was $0.5 \mathrm{~mm} / \mathrm{min}$ and three specimens were measured for each test condition.

\section{RESULTS AND DISCUSSION}

Microstructure and morphology: Fig. 1 shows the diffraction profile of $\mathrm{BCP}$ under different sintering temperature. The main characteristic peaks of $\mathrm{BCP}$ with containing hydroxyapatite and $\beta$-TCP are respectively marked by solid triangle symbol and solid cycle symbol. It can be concluded that all the samples exhibited similar XRD patterns. The characteristic peaks of 17.020, 27.90, -310, 34.480, 39.860 and 49.70 are assigned to the presence of $\beta$-TCP. The characteristic peaks of hydroxyapatite are mainly located at 25.920, 31.860, 32.240, 32.940 and 46.760 , respectively. Furthermore, it was seen that the intensity of the peaks increases with an increase of the sintering temperature and the width of the peaks exhibits decreasing trend as the sintering temperature improved. This suggests that the sintering temperature has perceivable effect on the characteristics of BCP. With increased sintering temperature, both the crystallinity and crystallite size of the BCP powder increased.

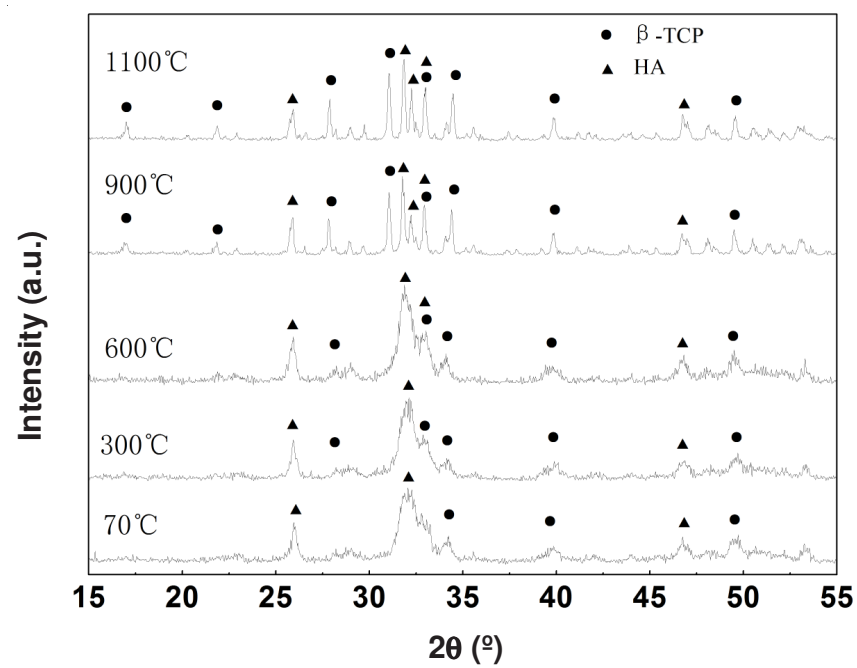

Fig. 1. X-ray powder diffraction profiles of samples under different sintering temperature
Fig. 2 shows the SEM images of porous BCP. It can be seen that the microstructure of porous BCP exits micro-pores. Furthermore, the porosity increased with the rise of stearic acid (Fig. 2a-2d). This result indicates that the porosity can be controlled by adjusting the content of stearic acid. On the other hand, while porous BCP is used as tissue engineering scaffold material, the micro-pore structure is beneficial to the growth of chondrocytes and effectively improves the interfacial bonding strength between implant material and natural tissue.
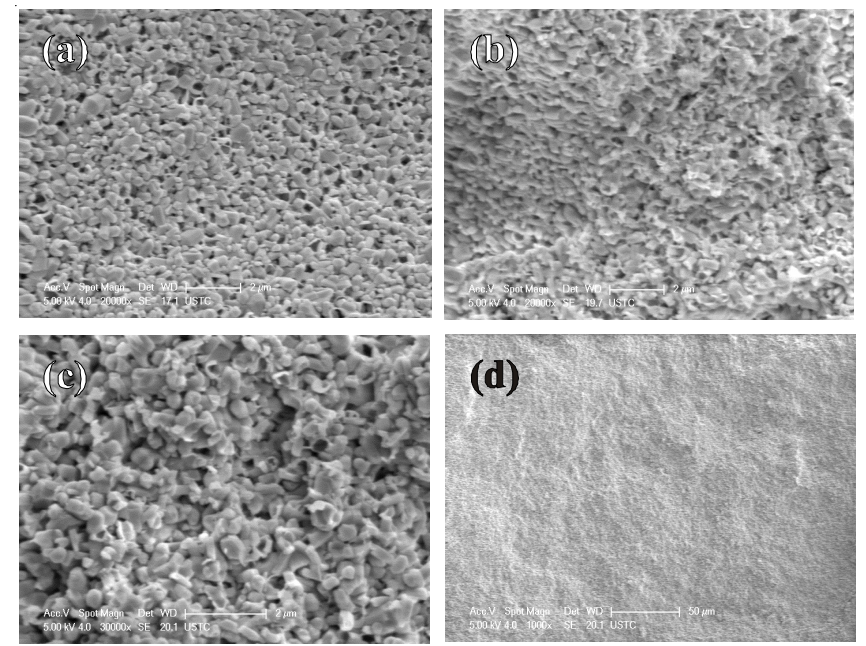

Fig. 2. Typical scanning electron micrographs of the porous biphasic calcium phosphate sintered with different stearic acid content (a) 60 wt $\%$, (b) 30 wt \%, (c) and (d) 0 wt \%

FTIR studies: Fig. 3 shows the typical FTIR spectra of $\mathrm{BCP}$ under different sintering temperature. FTIR spectra indicate that all the samples exhibit the characteristic bands of phosphate groups and characteristic bands of $\mathrm{OH}$ - group. In Fig. 3, $561 \mathrm{~cm}^{-1}$ and $602 \mathrm{~cm}^{-1}$ are assigned to O-P-O angle deformation vibration. The strongest peak at $1100-1050 \mathrm{~cm}^{-1}$ is attributed to the stretching vibration of phosphate group. The stretching vibration peak of water of crystallization occurs at $3440 \mathrm{~cm}^{-1}$ and the bending peak is at $1640 \mathrm{~cm}^{-13,6-8}$.

It should be noted that the weak bands originating from stretching vibrations of $\mathrm{CO}_{3}{ }^{2-}$ ions at $1380 \mathrm{~cm}^{-1}$ was observed. This result indicated that $\mathrm{BCP}$ synthesized without any carbonate additives has also contained a small fraction of $\mathrm{CO}_{3}{ }^{2-}$ substitutions. It is well known that inorganic constituents of human hard tissue contain 3-5 \% $\mathrm{CO}_{3}{ }^{2-}$. Therefore, from the perspective of bionics, carbonate-containing calcium phosphate is closer to the constituents of human hard tissues and is beneficial for its using as a tissue engineering implant materials.

Compressive strength: Fig. 4 shows the change behaviour of compressive strength and porosity with the stearic acid content. It can be concluded that the compressive strength of the porous BCP decreased with the rise of stearic acid content. Contrary, the porosity increased with the rise of stearic acid. For example, the compressive strength decreased rapidly from 56.87 to $0.88 \mathrm{MPa}$ while the stearic acid rising from 0 to $60 \mathrm{wt} \%$. On the other hand, the porosity increased from 2.56 to $78.89 \%$ as the stearic acid rising from 0 to $60 \mathrm{wt} \%$. The result indicates that the compressive strength of the porous $\mathrm{BCP}$ can be adjusted by controlling the content of stearic acid. 


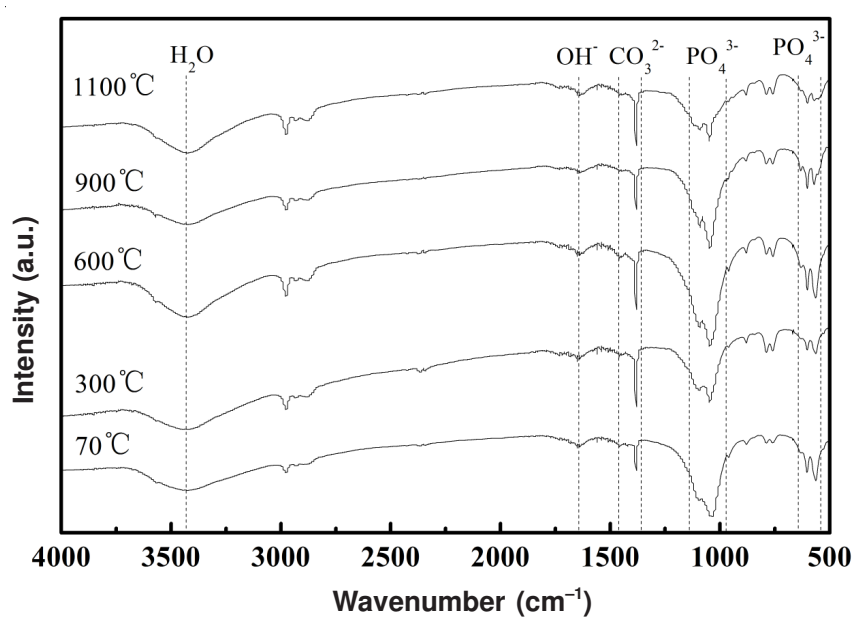

Fig. 3. FTIR spectra of biphasic calcium phosphate under different sintering temperature

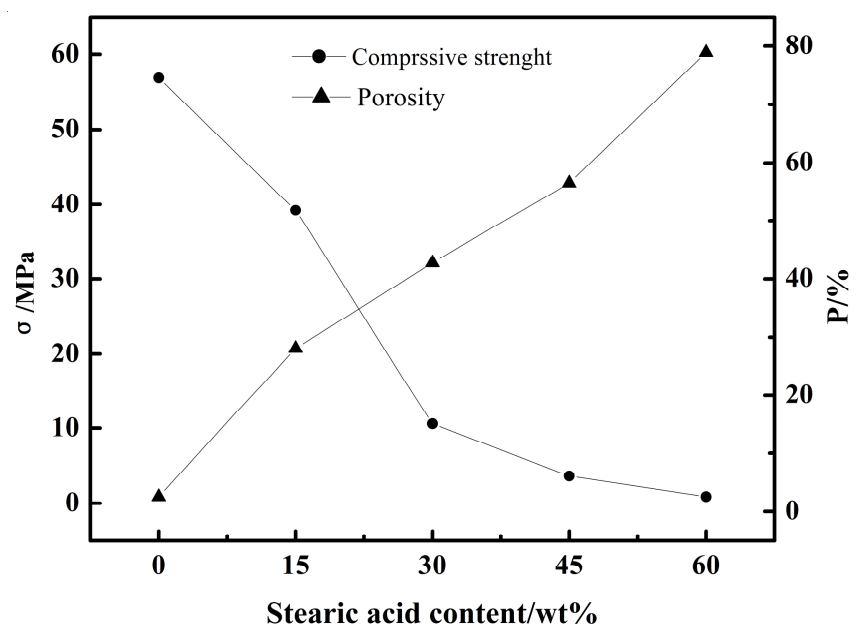

Fig. 4. Change behaviour of compressive strength and porosity with the stearic acid content

\section{Conclusion}

In this study, the porous biphasic calcium phosphate was successfully fabricated. The SEM observation conformed that the porous BCP scaffolds exhibit abundant porous structure and this special porous structure is beneficial to the growth of chondrocytes and effectively improves the interfacial bonding strength between implant material and natural tissue. The compressive mechanical properties revealed that the compressive strength of the porous bio-ceramic decreased with the rise of stearic acid content and porosity. Furthermore, the compressive strength can be controlled by adjusting the content of stearic acid.

\section{ACKNOWLEDGEMENTS}

The authors acknowledged the financial support provided to this work by the National Natural Science Foundation of China (Project No. 51175004).

\section{REFERENCES}

1. X.Y. Guo, J.E. Gough, P. Xiao, J. Liu and Z.J. Shen, J. Biomed. Mater. Res. A, 82, 1022 (2007)

2. H.L. Dai, X.Y. Wang, Y.C. Han, X. Jiang and S.P. Li, J. Mater. Sci. Technol., 27, 431 (2011).

3. B. Li, X.N. Chen, B. Guo, X.L. Wang, H.S. Fan and X.D. Zhang, Acta Biomater, 5, 134 (2009).

4. E.M. Christenson, K.S. Anseth, L. Beucken, C.K. Chan, B. Ercan and J.A. Jansen, J. Orthop. Res., 25, 11 (2007).

5. J.H. Park, J.Y. Bae, J. Shim and I. Jeon, Mater. Characteriz., 71, 103 (2012).

6. Y.C. Fu, M.L. Ho, S.C. Wu, H.S. Hsieh and C.K. Wang, J. Mater. Sci. Eng. C, 28, 1149 (2008).

7. Y.K. Liu, D.D. Hou and G.H. Wang, Mater. Chem. Phys., 86, 69 (2004).

8. W.H. He, R.K. Tang and X.R. Xu, Chin. J. Inorg. Chem., 27, 1233 (2011). 